\title{
Suppression of ID1 expression in colon cancer cells increases sensitivity to 5 -fluorouracil
}

\author{
Tomasz Przybyła1, Monika Sakowicz-Burkiewicz ${ }^{1 凶}$, Izabela Maciejewska', Hanna Bielarczyk² \\ and Tadeusz Pawełczyk ${ }^{1}$
}

'Department of Molecular Medicine, 2Departemnt of Laboratory Medicine, Medical University of Gdansk, Gdańsk, Poland

\begin{abstract}
Adjuvant chemotherapy with 5-fluorouracil remains the basic treatment for patients with advanced colorectal carcinoma. The major obstacle in successful treatment is the ability of CRC cells to acquire chemoresistance. Here we examined the impact of ID1 silencing on the sensitivity of CRC cells to 5-FU. To suppress ID1 expression in HT-29 and HCT-116 cells the cells were transduced with a lentiviral vector carrying the ID1 silencing sequence. Cells with silenced ID1 showed altered expression of epithelial and mesenchymal markers and exhibited increased proliferation rate compared to the parental cells. HCT-116 cells with suppressed ID1 became sensitized to 5-FU and this was not observed in HT-29 cells. Silencing ID1 resulted in altered expression of genes encoding enzymes metabolizing 5-FU. HT-29 cells with suppressed ID1 had significantly reduced mRNA level for thymidine phosphorylase, uridine-cytydine kinase 2 and dihydropyrimidine dehydrogenase. ID1 suppression in HCT-116 cells resulted in an increase of mRNA level for thymidine phosphorylase, thymidine kinase and uridine-cytydine kinase 2 with concurrent drop of dihydropyrimidine dehydrogenase and thymidylate synthetase mRNA levels. In conclusion, ID1 expression impacts the sensitivity of colon cancer cells to 5-FU and may be considered as a potential predictive marker in CRC treatment.
\end{abstract}

Key words: colon cancer, ID1, 5-fluorouracil, TYMP, TK, UCK2, DYPD, TYMS.

Received: 07 September, 2016; revised: 06 February, 2017; accepted: 21 February, 2017; available on-line: 17 May, 2017

e-mail: ssak@gumed.edu.pl

Abbreviations: 5-FDHU, 5-fluoro-5,6-dihydrouracil; 5-FdUTP 5-fluoro-2'-deoxyuridine-5'-triphosphate; 5-FU, 5-fluorouracil 5-FUTP, 5-fluorouridine-5'-triphosphate; 7-AAD, 7-aminoaxtinomycin D; CDH1, E-cadherin; $\mathrm{CDH} 2, \mathrm{~N}$-cadherin; $\mathrm{CRC}$, colorectal carcinoma; CTNN $\beta 1$, beta-catenin; DMSO, dimethyl sulfoxide; DPYD, dihydropyrimidine dehydrogenase; DT, doubling time; dTMP, 2'-deoxythymidine-5'-monophosphate; EMT, epithelial to mesenchymal transition; F-BAL, fluoro- $\beta$-alanine; FBS, fetal bovine serum; FdUMP, 5-fluoro-2'-deoxyuridine-5'-monophosphate; FdUR, 5'-deoxy5-fluorouridine; FGF, fibroblast growth factor; FN1, fibronectin1; FUMP, 5-fluorouridine-5'-monophosphate; FUR, 5-fluorouridine; GFP, green fluorescent protein; HLH, helix-loop-helix; ID1, inhibitor of differentiation 1; LIF, leukemia inhibitory factor; MET, mesenchymal epithelial transition; MTT, 3-[4,5-dimethylthiazol-2-yl]-2,5diphenyltetrazolium bromide; TCF3, transcription factor 3; TK1, thymidine kinase 1; TP53, tumor protein p53; TWIST1, twist family bHLH transcription factor 1; TYMP, thymidine phosphorylase; TYMS, thymidylate synthase; UCK2, uridine-cytydine kinase 2; UMPS, uridine monophosphate synthetase; UPP1, uridine phosphorylase 1; VIM, vimentin

\section{INTRODUCTION}

Colorectal carcinoma (CRC) is diagnosed in about 1 million people every year. It is the most frequent gas- trointestinal neoplasm (cancer) and one of the most fatal cancers in general (Kelder et al., 2006). In most cases surgery remains the basic and sufficient treatment of patients with CRC at stage I and II, however, for patients with more advanced cancer (stage III and IV) the standard treatment following resection includes adjuvant chemotherapy. Implementation of such a treatment prolongs progression-free survival and overall survival (Lombardi et al., 2010). Adjuvant chemotherapy was also shown to highly improve 5-year survival in stage IV patients with isolated liver or lung metastases (Cassidy \& Graham, 2012). 5-fluorouracil (5-FU) is one of the earliest chemotherapeutic agents and it has been used successively in CRC treatment for over 50 years (Hammond et al., 2016). The drug operates through mechanisms involving inhibition of DNA replication and cell death. 5-fluoro-2'-deoxyuridine-5'-monophosphate (FdUMP), the primary metabolite of 5 -FU inhibits thymidylate synthase (TYMS), an enzyme producing 2'-deoxythymidine-5'-monophosphate (dTMP). Insufficient dTMP bioavailability disrupts DNA synthesis in the dividing cells. The alternative 5-FU metabolites, 5-fluorouridine-5'-triphosphate (5-FUTP) and 5-fluoro-2'-deoxyuridine-5'-triphosphate (5-FdUTP), undergo inclusion into DNA, which results in impaired translation and subsequent cell death (Cassidy \& Graham, 2012; Hammond et al., 2016).

The major obstacle in successful treatment with $5-\mathrm{FU}$ based adjuvant chemotherapy is the ability of CRC cells to acquire resistance (Hammond et al., 2016). Several mechanisms have been proposed to be responsible for the decrease in cancer cells sensitivity to 5-FU including: variable number of tandem repeats, microsatellite instability, single nucleotide polymorphisms occurring within genes encoding enzymes metabolizing 5-FU, and altered expression of 5-FU metabolizing enzymes (Hammond et al., 2016). Improvement of 5-FU adjuvant treatment efficacy remains one of the most important challenges in CRC management. One of the main approaches is identification of predictive biomarkers associated with specific response to chemotherapy, which firstly would allow to determine a group of patients benefiting from 5-FU treatment and could exclude the non-responsive ones. Secondly, it may be useful in development and application of novel therapies combining 5-FU and selective agents capable of targeting specific signaling pathways in tumor. It was initially shown that targeting vascular endothelial growth factor in addition to standard chemotherapy improved outcomes of patients with metastatic CRC. However, recent clinical trials demonstrated that patients with CRC stage III did not benefit from such combined regimen. Thus, understanding the tumor biology through identification of biomarkers, which determine the success or failure of treatment at specific 
CRC stage, seems to be crucial step in developing a new, more effective treatment for CRC patients (Oyan, 2012).

The inhibitor of differentiation 1 (ID1) belongs to the family of helix-loop-helix (HLH) transcription regulators. These proteins achieve transcriptional activity by forming heterodimers with other members of the family. ID1, however, lacks the ability to bind DNA and plays a role of dominant negative regulator of its dimerization partners (Ling et al., 2014). ID1 was shown to promote chemoresistance of esophageal and pancreatic cancer cells (Li et al., 2014). On the other hand, it was reported that ID1 is a favorable predictor for surgically treated non-small-cell lung cancer patients undergoing chemotherapy (Cheng et al., 2014). Research on the role of ID1 in breast and gastric cancer and glioma revealed that it is also involved in epithelial to mesenchymal transition (EMT) which is considered one of the mechanisms promoting chemoresistance of cancer cells (Tobin et al., 2011; Peng et al., 2014; Sánchez-Tilló et al., 2014). Still, the direct mechanisms of ID1 related chemoresistance in cancer cells are not known, moreover, not much attention in this context has been paid regarding colon cancer. The aim of this work was to examine the relation between the ID1 expression level and the sensitivity of colon cancer cells to $5-\mathrm{FU}$.

\section{MATERIALS AND METHODS}

Cell cultures. All experiments were conducted on colon cancer cell lines HT-29 and HCT-116 (ATCC, Rockville, MD, USA). Cells were cultured in DMEM enriched with $10 \%$ fetal bovine serum (FBS), penicillin $(10 \mathrm{U} / \mathrm{ml})$ and streptomycin $(100 \mu \mathrm{g} / \mathrm{ml})$ under standard conditions $\left(37^{\circ} \mathrm{C}, 5 \% \mathrm{CO}_{2}\right)$. The culture medium was replaced twice a week and cells were passaged at $70 \%$ confluence.

Transduction procedure. ID1 silencing shRNA sequence CTCTACGACATT'TCAAGAGAATGTCGTAGAGCAGCACGTCTTT'TTC (Oligos, Warsaw, Poland) was subcloned into lentiviral vector pLL3.7 (Addgene, Cambridge, MA, USA) to generate pLL3.7-shID1 construct. Scrambled oligonucleotide GGTT'TATGCGCTCGATCTCTA (Oligos, Warsaw, Poland) was used to obtain pLL3.7-scramble plasmid, which served as a negative control. The packaging cells HEK-293T (ATCC, Rockville, MD, USA) were transfected with envelope plasmid pMD2.G, and a packaging plasmid psPAX2 (Adgene, Cambridge, MA, USA) together with pLL3.7shID1 or pLL3.7-scramble. X-treme Gene 9 (Roche, Mannheim, Germany) was used as a transfection agent. Transfected HEK-293T cells were then incubated for 48 hours to allow generation and replication of the virus. HEK-293T medium containing viral particles was subsequently used to transduce HT-29 and HCT-116 cells. Negative control virus generated control (parental) cells, while vector expressing shRNA targeting ID1 produced cells with suppressed ID1 expression (HT-29shID1 and HCT-116shID1). Successfully transduced cells expressed green fluorescent protein (GFP) and number of GFP positive cells was counted under fluorescent microscope (Leica, Wetzlar, Germany). When at least $80 \%$ of cancer cells exhibited green fluorescence, the transduction procedure was finished.

MTT assay. Cells viability in appropriate experiments was estimated on the basis of mitochondrial dehydrogenase activity. In living cells 3-[4,5-dimethylthiazol2-yl]-2,5-diphenyltetrazolium bromide (MTT) (Sigma-Aldrich, Poznan, Poland) is converted by the enzyme to insoluble formazan and the extent of conversion reflects the total number of viable cells (Berridge et al., 1996). After the end of particular experiment the cells were incubated for two hours in fresh DMEM containing 0.5 $\mathrm{mg} / \mathrm{ml} \mathrm{MTT}$ at $37^{\circ} \mathrm{C}$. Next, the medium was removed and formazan crystals were dissolved in $0.2 \mathrm{ml}$ of acidic isopropanol. Finally, the absorbance of formazan was measured in a microplate reader (1420 multilabel Counter VICTOR3, PerkinElmer, Waltham, MA, USA) at 570 $\mathrm{nm}$ and at $690 \mathrm{~nm}$ (background subtraction).

Proliferation assays. Cells were seeded onto 24well plates at a density of $1.5 \times 10^{4} /$ well and cultured in complete medium or medium lacking FBS. Medium was replaced every day. Measurement of cell viability with M'T'T test was conducted after 24 hours and repeated every day for 124-hour period. The growth curves were generated and population doubling times (DT) were calculated on the basis of exponential growth periods (see Statistical analysis).

5-FU dose response assays. Cancer cells were seeded onto 24 -well plates at a density of $1.5 \times 10^{4} /$ well and left for 24 hours to attach to plate bottom. Next day the medium was replaced with fresh one containing 5-FU (Sigma-Aldrich, St. Louis, MO, USA) at appropriate concentrations. The control cells were cultured in medium with dimethyl sulfoxide (DMSO) (Sigma-Aldrich, St. Louis, MO, USA) at the concentration used to dissolve 5 -FU. After 48 hours of incubation the cell culture medium was removed and cell viability was evaluated with MTT test. Concentration at which 50\% reduction of cell viability occurred $\left(\mathrm{IC}_{50}\right)$ was determined (see Statistical analysis).

Flow cytometric analysis. Cancer cells were seeded onto $60 \mathrm{~mm}$ plates at density of $1.5 \times 10^{5}$ cells/plate and cultured overnight. Next day the medium was replaced with fresh one containing 5-FU at appropriate concentrations. The control cells were cultured in medium with equal amount of DMSO. After 48 hours of incubation the experimental medium was removed and the cell viability was evaluated by flow cytometric analysis. Control and experimental cells were stained with 7-aminoaxtinomycin D (7-AAD) and annexin V-PE from PE Annexin V Apoptosis Detection Kit I (BD Biosciences, San Diego, CA, USA) according to manufacturer protocols. Analysis was conducted on FACScan flow cytometer (BD Biosciences, San Diego, CA, USA). The cells negative for annexin $\mathrm{V}$ and 7-AAD staining were considered as viable, while early apoptotic cells were marked by decreased size and staining with annexin V. Late apoptotic cells exhibited diminished diameter and were positive both for annexin $\mathrm{V}$ and 7-AAD staining, while necrotic cells were defined by size ranging between normal and increased and presence/emission of 7-AAD signal.

Reverse transcription-quantitative PCR. Total RNA Prep Plus Kit (A\&A biotechnology, Gdynia, Poland) was used to isolate RNA from the cells. The expression level of each gene was analyzed with One-Step Real-Time PCR carried out using LightCycler 2.0 (Roche, Basel, $\mathrm{CH}$ ). Path-ID Multiplex One-Step RT-PCR Kit (ThermoFisher Scientific, Waltham, MA, USA) and appropriate probes from Universal ProbeLibrary (Roche, Basel, $\mathrm{CH})$ were applied to prepare samples. Each transcript level was normalized to ACTIN BETA (ACTB) mRNA. Table 1 shows the list of primer sequences, TaqMan probes and cycling conditions.

Protein analysis. Qualitative determination of ID1 level in parental and ID1 suppressed cancer cells was performed using Western Blot. Protein samples were prepared as described previously (Maciejewska et al., 2014) and loaded on gradient (4-20\%) SDS-PAGE gel. 
Table I. List of primers, TaqMan probes and cycling conditions used for RT-PCR.

\begin{tabular}{|c|c|c|}
\hline Gene $^{*}$ & Primers & TaqMan probe \\
\hline ID1 & $\begin{array}{l}\text { CTGGACGAGCAGCAGGTAA } \\
\text { CTCCAACTGAAGGTCCCTGA }\end{array}$ & $\begin{array}{l}\text { Universal ProbeLibrary } \\
\text { Probe \# } 6 \text { (Roche) }\end{array}$ \\
\hline FN1 & $\begin{array}{l}\text { TTGCTCTTTCTAACCATTGTA- } \\
\text { ATTCT } \\
\text { TATTTCCCTTGCAGGCAATC }\end{array}$ & $\begin{array}{l}\text { Universal ProbeLibrary } \\
\text { Probe \# } 39 \text { (Roche) }\end{array}$ \\
\hline VIM & $\begin{array}{l}\text { TGGTCTAACGGTTTCCCCTA } \\
\text { GACCTCGGAGCGAGAGTG }\end{array}$ & $\begin{array}{l}\text { Universal ProbeLibrary } \\
\text { Probe \# } 56 \text { (Roche) }\end{array}$ \\
\hline $\mathrm{CDH} 2$ & $\begin{array}{l}\text { ACGCTCTCCCTCCCTGTT } \\
\text { GGACTCGCACCAGGAGTAAT }\end{array}$ & $\begin{array}{l}\text { Universal ProbeLibrary } \\
\text { Probe \# } 17 \text { (Roche) }\end{array}$ \\
\hline $\mathrm{CDH} 1$ & $\begin{array}{l}\text { CAGGCTCAAGCTATCCTTGC } \\
\text { AGTCATGCGTAGTGGTGCAT }\end{array}$ & $\begin{array}{l}\text { Universal ProbeLibrary } \\
\text { Probe \# } 33 \text { (Roche) }\end{array}$ \\
\hline CTNNB1 & $\begin{array}{l}\text { CCATITAAGCCTCTCGGTCT } \\
\text { CAGACCTTCCTCCGTCTCC }\end{array}$ & $\begin{array}{l}\text { Universal ProbeLibrary } \\
\text { Probe \# } 74 \text { (Roche) }\end{array}$ \\
\hline$D P Y D$ & $\begin{array}{l}\text { GGGATTGCAAAGCGAACTAC } \\
\text { TCACAGCTCTCAAAGCAATAGG }\end{array}$ & $\begin{array}{l}\text { Universal ProbeLibrary } \\
\text { Probe \# } 25 \text { (Roche) }\end{array}$ \\
\hline TYMP & $\begin{array}{l}\text { CATTCTCAGTAAGAAACTCGTGGA } \\
\text { GGCCCCTCCGAACTTAAC }\end{array}$ & $\begin{array}{l}\text { Universal ProbeLibrary } \\
\text { Probe \# } 77 \text { (Roche) }\end{array}$ \\
\hline TK1 & $\begin{array}{l}\text { CAGCTTCTGCACACATGACC } \\
\text { CGTCGATGCCTATGACAGC }\end{array}$ & $\begin{array}{l}\text { Universal ProbeLibrary } \\
\text { Probe \# } 79 \text { (Roche) }\end{array}$ \\
\hline TYMS & $\begin{array}{l}\text { GGGCAGCCCTCTCCTTTA } \\
\text { GCAGTTGGTCAACTCCCTGT }\end{array}$ & $\begin{array}{l}\text { Universal ProbeLibrary } \\
\text { Probe \# } 43 \text { (Roche) }\end{array}$ \\
\hline UMPS & $\begin{array}{l}\text { AGGAAAGAAACAAAGGATTATG- } \\
\text { GA } \\
\text { TGGTGACAACATCTTCAATGATTA }\end{array}$ & $\begin{array}{l}\text { Universal ProbeLibrary } \\
\text { Probe \# } 2 \text { (Roche) }\end{array}$ \\
\hline UPP1 & $\begin{array}{l}\text { AGAAACTGAGCAAGGCCTGA } \\
\text { CACAACAGGGGATITGGAC }\end{array}$ & $\begin{array}{l}\text { Universal ProbeLibrary } \\
\text { Probe \# } 62 \text { (Roche) }\end{array}$ \\
\hline UCK2 & $\begin{array}{l}\text { ATCCAGTGGTGCTTGGTTCT } \\
\text { CCTAAACACTTGGTCCACACAC }\end{array}$ & $\begin{array}{l}\text { Universal ProbeLibrary } \\
\text { Probe \# } 4 \text { (Roche) }\end{array}$ \\
\hline ACTB & $\begin{array}{l}\text { CAACCGCGAGAAGATGAC } \\
\text { GTCCATCACGATGCCAGT }\end{array}$ & $\begin{array}{l}\text { Universal ProbeLibrary } \\
\text { Reference Gene Assay } \\
\text { Roche, Human ACTB } \\
\text { Gene Assay }\end{array}$ \\
\hline
\end{tabular}

Reverse transcription: $48^{\circ} \mathrm{C}(10 \mathrm{~min}), 95^{\circ} \mathrm{C}(10 \mathrm{~min})$. Amplification: $95^{\circ} \mathrm{C}(10 \mathrm{~s}), 60^{\circ} \mathrm{C}$ (45 s). *The human genes are listed according toHUGO Gene Nomenclature Committee

After electrophoresis proteins were transferred to PVDF membranes by electro blotting and blocked by incubation in 3\% bovine serum albumin. Afterwards, membranes were incubated overnight with goat ani-ID1 antibody (1:500 dilution) (R\&D Systems, MN, USA) and subsequently washed and incubated with alkaline phosphatase-conjugated rabbit anti-goat $\operatorname{IgG}$ secondary antibody (Santa Cruz Biotechnology, Santa Cruz, CA, USA). Reference protein ACTIN BETA was detected with mouse anti-ACTB monoclonal antibody (Sigma-Aldrich, Poznan, Poland) and goat ALP-anti-mouse IgG secondary antibody (Santa Cruz Biotechnology, Santa Cruz, CA, USA). Quantitative determination of ID1 protein levels was carried out with ELISA test (\#MBS911748) (MyBioSource, Inc., San Diego, CA, USA) according to manufacturer's instruction. Standards curves were obtained with online ElisaAnalysis Platform (elisakit.com, Scoresby, VIC, Australia).

Statistical analysis. GraphPad Prism 5.0 (La Jolla, CA, USA) software was used to generate nonlinear trend lines. In proliferation assays population DTs were calculated from growth curves according to exponential growth model. In 5-FU dose response assays concentration at which $50 \%$ reduction of cell viability occurred $\left(\mathrm{IC}_{50}\right)$ was determined from dose response curves with four-parameter dose response model. In both models differences between control and experimental group were determined with extra-sum-of squares $\mathrm{F}$ test. In other cases differences between groups were examined by Student's $t$-test. $P$ values below 0.05 were considered significant.

\section{RESULTS}

\section{The impact of ID1 gene suppression on ID1 protein content in the cell}

Transduction procedure of colon cancer cells resulted in a significant reduction of ID1 expression (Fig. 1). The ID1 transcript level in parental HT-29 cells was $0.262 \pm 0.011$ compared to $0.005 \pm 0.001$ observed in HT-29shID1 cells (53-fold decrease). In HCT-116shID1 cells the relative ID1 transcript level was reduced 68 fold compared to parental HCT116 cells (from $0.674 \pm 0.025$ to $0.010 \pm 0.001$ ) (Fig. 1B). Western blot analysis showed that the ID1 protein content decreased in transduced HT-29 and HCT116 cell lines (Fig. 1C). Quantitative analysis of ID1 protein in parental HT-29 and HCT116 cell lines yielded $2.61 \pm 0.30$ and $2.81 \pm 0.26$ $\mathrm{pg}$ of ID1 protein $/ 10^{6}$ cells, respectively. In HT-29shID1 and HCT116shID1 cells the ID1 protein levels averaged $1.62 \pm 0.13 \mathrm{pg} / 10^{6}$ cells and $1.03 \pm 0.10 \mathrm{pg} / 10^{6}$ cells, respectively (Fig. 1D). The efficiency of ID1 suppression both at mRNA and protein level was higher in HCT$116 \mathrm{sh} I D 1$ cells and resulted in significantly lower amount of ID1 protein compared to HT29shID1cells.

\section{Altered expression of epithelial and mesenchymal markers in cells with silenced ID1}

To examine the impact of ID1 suppression on possible epithelial to mesenchymal transition (EMT) we analyzed expression of selected epithelial and mesenchymal markers. We observed that in cells with silenced ID1 the expression of epithelial markers i.e. E-cadherin (CDH1) and beta-catenin (CTNNB1) was altered differently (Fig. 2). The transcript level of CDH1 increased in both cell lines, however, the change was significant only in HCT-116shID1 cells. ID1 suppression resulted in significant elevation of CTNNB1 transcript levels in both cell lines, although greater degree of change was observed in HT-29shID1 compared to HCT-116shID1 cells (6.5-fold versus 1.3fold, respectively). We noted that suppression of ID1 resulted in changes in expression of mesenchymal markers (N-cadherin, vimentin and fibronectin) in examined cells. The expression of $\mathrm{N}$-cadherin (CDH2) decreased 4.9-fold, and increased 3.4-fold in HT-29shID1 and HCT-116shID1 cells, respectively (Fig. 2). The expression level of vimentin (VIM) changed differently in HT-29 and HCT-116 cells after ID1 silencing. HT-29shID1 cells showed 17fold increase in VTM mRNA level compared to control cells, however, it should be pointed that the transcript level was very low before as well as after ID1 knockdown $\left(1.0 \times 10^{-8} \pm 10.0 \times 10^{-10}\right.$ and $2.4 \times 10^{-7} \pm 1.0 \times 10^{-8}$, respectively). Low VIM transcript level was also observed in parental HCT-116 $\left(7.0 \times 10^{-8} \pm 2.0 \times 10^{-8}\right)$, and silencing ID1 expression resulted in a drop of this mRNA levels below the detection limit. The fibronectin1 (FN1) expression was undetectable in both parental HT-29 and 


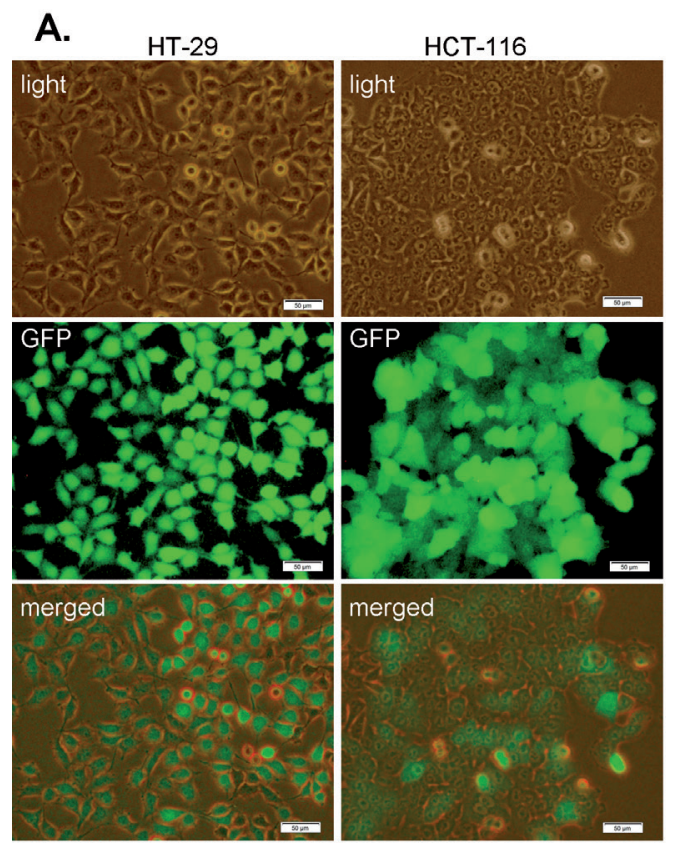

B.

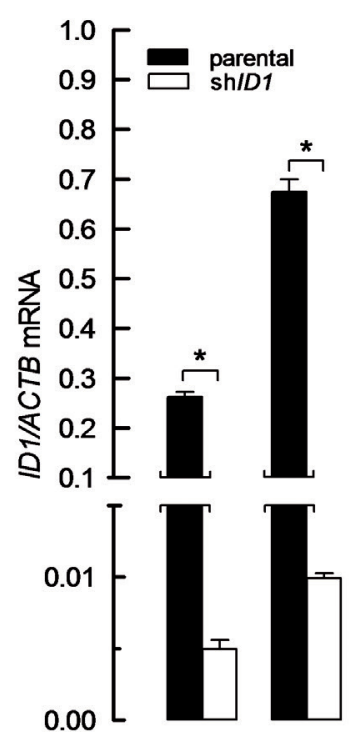

C.

D.

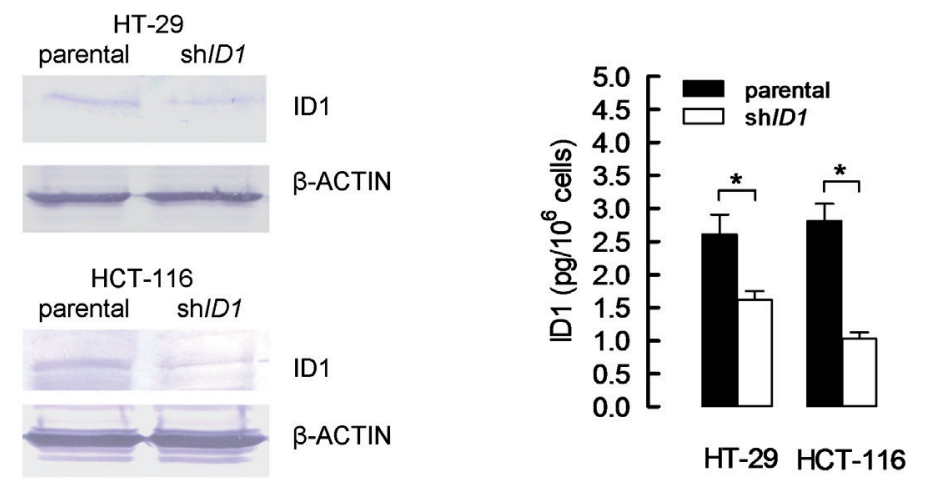

Figure 1. Efficiency of ID1 suppression in HT-29 and HCT-116 cells.

Transduction with lentiviral pLL3.7 scrambled vector generated control (parental) cells while introduction of pLL3.7-sh/D1 vector encoding the ID1 silencing sequence (shID1) produced cells with suppressed ID1 expression (HT-29sh/D1 and HCT-116sh/D1). (A) Presentation of HT-29sh/D1 and HCT-116sh/D1 cells in normal light and under a fluorescent microscope (GFP). Efficient transduction resulted in GFP expression. Merged pictures are shown at the bottom. (B) Relative ID1 transcript levels determined by quantitative PCR. Results were normalized to ACTB mRNA level and are presented as fold of change between parental and sh/D1 cells. * Indicates significant difference compared to control cells $(P<0.05)$. (C) Qualitative examination of protein content by Western Blot. ACTIN BETA was used as a reference protein. (D) An enzyme-linked immunosorbent assay (ELISA) was used to quantitatively determine ID1 protein level in control and pLL3.7-sh/D1 transduced HT-29 and HCT116 cells. ${ }^{*} P<0.05$ vs control.

HCT-116 cells, however, suppression of ID1 resulted in a rise of this transcript level up to $1.3 \times 10^{-3} \pm 1.6 \times 10^{-4}$ and $2.6 \times 10^{-3} \pm 1.0 \times 10^{-4}$ in HT-29shID1 and HCT-116shID1 cell lines respectively (Fig. 2).

\section{Suppression of ID1 expression affects cell proliferation}

In the next step of our investigation we examined the impact of ID1 suppression on cells proliferation rate. Comparison of both parental cell lines showed that HT-29 cells exhibited higher proliferation rate (DT= $27 \mathrm{~h}$; 95\%CI: 21-24) compared to parental HCT-116 (DT=33 h; 95\%CI: 29-40) (Fig. 3). Suppression of ID1 enhanced proliferation of investigated cells, the doubling time dropped to $23 \mathrm{~h}(95 \% \mathrm{CI}: 21-24)$ and $30 \mathrm{~h}(95 \% \mathrm{CI}$ :
HT-29 HCT-116

27-33) in HT-29shID1 and HCT$116 \mathrm{sh} I D 1$ cell lines respectively. HT-29 and HCT-116 cell lines, independently of ID1 expression, showed rather similar progression of growth curves. Lag phase lasted approximately $48 \mathrm{~h}$ and afterwards cells approached phase of exponential growth. However, only HT-29 cells, both parental and transduced, reached the stationary step, which occurred after $120 \mathrm{~h}$. FBS is a source of growth factors boosting cellular proliferation. To examine whether ID1 suppression alters the proliferation rates of investigated cells irrespectively of exogenous growth stimuli we evaluated growth of cell cultures under serum-starvation conditions. In HT-29 line a peak of density occurred at 120th and 96th hour for parental and transduced cells respectively and was followed by constant decline. During the last three days of measurement parental HT-29 cells showed higher proliferation rate compared to HT-29shID1 cells (Fig. 3). Parental HCT116 cells as well as HCT-116shID1 cells were unable to grow without FBS supplementation. Nevertheless, none of the examined cell lines reached the exponential growth phase; thus, the DTs remained undetermined under serum-starvation conditions.

\section{Effect of ID1 suppression on the} cells sensitivity to 5-fluorouracil

We examined whether suppression of ID1 affected the colon cancer cell lines response to 5-FU. The cells underwent treatment with increasing concentrations of 5-FU ranging from 0.01 to $100 \mu \mathrm{M}$, and subsequently the concentration at which $50 \%$ of growth inhibition occurred $\left(\mathrm{IC}_{50}\right)$ was calculated. Parental and transduced HT-29 cells did not show significant differences in response to 5 -FU and shared $\mathrm{IC}_{50}$ value was $6.2 \mu \mathrm{M}$ (95\%CI: 4.0-9.9) (Fig. 4). We observed that ID1 expression level modulated the response of HCT-116 cell line to 5-FU. 50\% growth inhibition of parental HCT-116 cells was achieved at concentration of $12.4 \mu \mathrm{M}$ (95\% CI: 7.5-20.6), whereas $\mathrm{IC}_{50}$ for HCT-116shID1 averaged $1.5 \mu \mathrm{M}$ (95\%CI: $0.8-2.7$ ) (Fig. 4).

Examination of HT-29 cell line by flow cytometry showed that under normal culture conditions $92.53 \pm 0.78 \%$ of parental HT-29 cells were viable while the majority of dead cells was at the stage of late apoptosis (Table 2). ID1 suppression significantly increased proportions of late apoptotic and necrotic fractions resulting in diminished viability of HT-29shID1 cells $(76.40 \pm 5.00 \%)$. Viability of parental HCT-116 


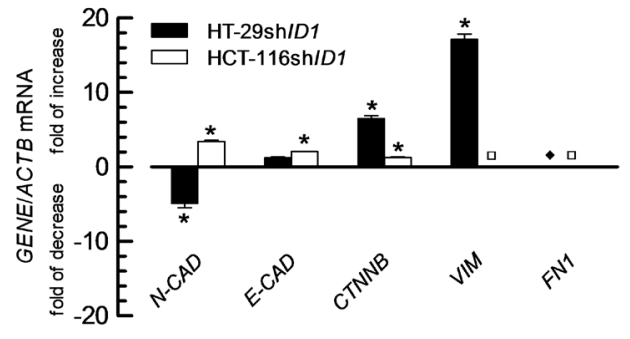

Figure 2. Impact of ID1 suppression on the expression of epithelial and mesenchymal markers.

Determination (quantitative PCR) of relative transcript levels of the epithelial markers: CDH1 (E-cadherin) and CTNNB1 (beta catenin); and the mesenchymal markers: FN1 (fibronectin), VIM (vimentin), $\mathrm{CDH} 2$ (N-cadherin). Results were normalized to ACTB mRNA level and are presented as fold of change between transduced and parental cells. ${ }^{*}$ indicates significant difference compared to control cells $(P<0.05) .(\square)$ Indicates that relative transcript level in parental or pLL3.7-shID1 transduced cells was below the detection limit in HT-29 or HCT-116 lines respectively.
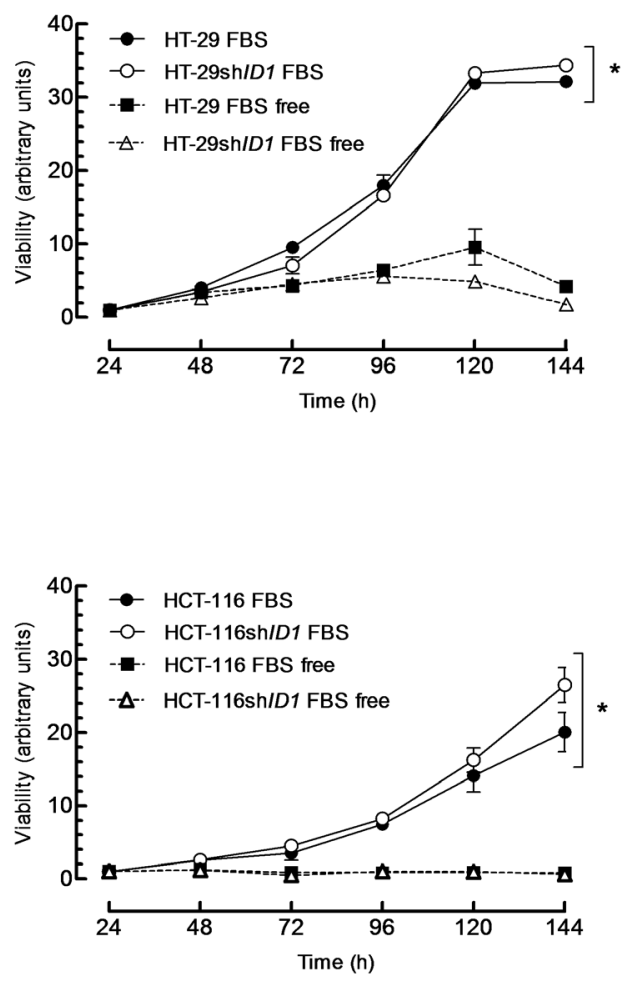

Figure 3. The effect of IDI suppression on the proliferation of colon cancer HT-29 and HCT-116 cells.

The cells were plated onto 24 -well plates at a density of $1.5 \times 10^{4 /}$ $\mathrm{ml} /$ well and were cultured in the presence or absence of $10 \% \mathrm{fe}-$ tal bovine serum (FBS) for time indicated, afterwards the cell viability was determined by MTT test. *Indicates significant difference in population doubling time (DT) values between control and shID1 cells $(P<0.05)$.

cells cultivated under standard conditions remained at $86.97 \pm 0.64 \%$ which was significantly less in comparison with parental HT-29 cells (Table 2). Decreased content of ID1 in HCT-116shID1 cells was associated with a decrease of cell viability $(65.42 \pm 2.22 \%)$. In both parental and transduced HCT-116 cells the second largest fraction beside viable cells consisted of early apoptotic cells. In the parental HCT-116 cell line early apoptotic cells averaged $9.67 \pm 1.80 \%$ and rose to $29.09 \pm 5.10 \%$ in HCT-116shID1 cells. Inclusion of $1 \mu \mathrm{M} 5-\mathrm{FU}$ to the cell culture resulted in a significant reduction of viable cells in each cell line and major enrichment was observed in
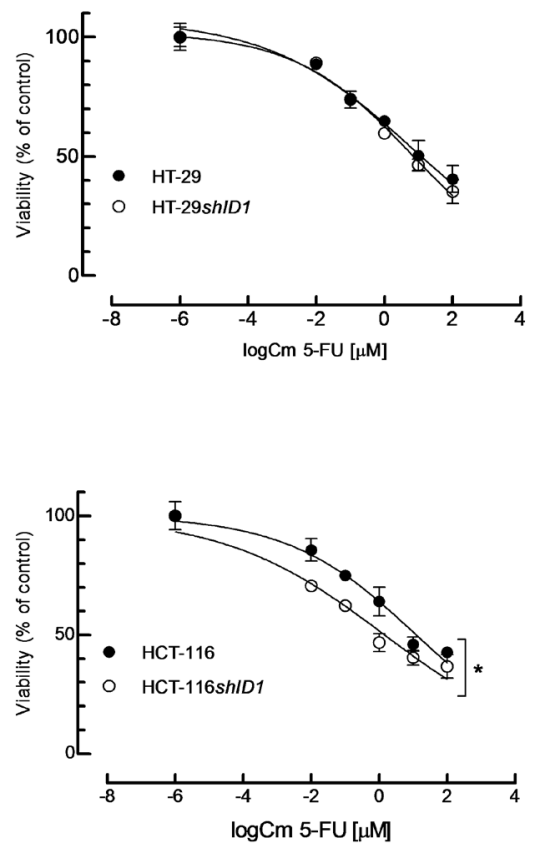

Figure 4. The effect of ID1 suppression on the sensitivity of colon cancer HT-29 and HCT-116 cells to 5-fluorouracil (5-FU). Parental and sh/D1 cells were cultured for 48 hours with addition of 5-FU at concentrations indicated. The cells viability was determined with MTT test. Untreated cells were maintained both in normal medium and in DMEM supplemented with an equal amount of solvent $(0.01 \%$ DMSO) used to dissolve 5 -FU. The results are expressed as the percentage viability of 5-FU treated cells in comparison to untreated cells. *Indicates significant difference in 5-FU concentrations at which $50 \%$ reduction of cell viability occurred $\left(\mathrm{IC}_{50}\right)$ between control and sh/D1 cells $(P<0.05)$.

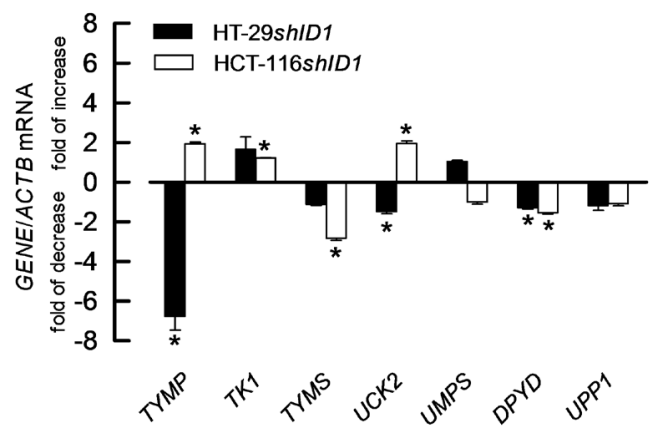

Figure 5. The Effect of ID1 suppression on the expression levels of genes encoding enzymes metabolizing 5-FU.

Determination of relative expression levels of genes encoding dihydropyrimidine dehydrogenase (DPYD), thymidine phosphorylase (TYMP), thymidine kinase 1 (TK1), thymidylate synthase (TYMS), uridine monophosphate synthetase (UMPS), uridine-cytidine kinase 2 (UCK2), and uridine phosphorylase 1 (UPP1) was performed using quantitative PCR. Results were normalized to ACTB mRNA level and are presented as fold of change between shID 1 and parental cells. *Indicates significant difference compared to control cells $(P<0.05)$.

fraction of early apoptotic cells. This was accompanied by a decreased fraction of late apoptotic and necrotic cells (Table 2).

\section{Impact of ID1 suppression on the expression level of} genes encoding enzymes metabolizing 5 -fluorouracil

Activity of 5-FU depends on its enzymatic conversion to metabolically active forms. Thus, we examined the expression of genes encoding major 5-FU metabolizing enzymes in order to assess possible impact of ID1 sup- 
Table 2. Impact of ID1 suppression on 5-FU-induced cell death. *Indicates significant difference $(P<0.05)$ between parental and transduced cells under particular conditions.

\begin{tabular}{|c|c|c|c|c|c|}
\hline Environment & Cell Line & Viable cells (\%) & Early apoptotic cells (\%) & Late apoptotic cells (\%) & Necrotic cells (\%) \\
\hline \multirow{2}{*}{ Control } & HТ-29 & $92.53 \pm 0.78 \%$ & $0.52 \pm 0.11 \%$ & $5.8 \pm 1.23 \%$ & $1.14 \pm 0.57 \%$ \\
\hline & HT-29 shID1 & $76.4 \pm 5.0 \% *$ & $0.93 \pm 0.06 \% *$ & $16.25 \pm 1.28 \% *$ & $6.42 \pm 0.42 \% *$ \\
\hline \multirow{2}{*}{$1 \mu \mathrm{M}$ 5-FU } & HT-29 & $71.66 \pm 3.19 \%$ & $21.69 \pm 1.13 \%$ & $6.58 \pm 1.24 \%$ & $0.07 \pm 0.01 \%$ \\
\hline & HT-29 shID1 & $57.85 \pm 2.42 \% *$ & $28.46 \pm 1.87 \% *$ & $12.57 \pm 0.99 \% *$ & $1.12 \pm 0.07 \% *$ \\
\hline Environment & Cell Line & Viable cells (\%) & Early apoptotic cells (\%) & Late apoptotic cells (\%) & Necrotic cells (\%) \\
\hline \multirow{2}{*}{ Control } & HCT 116 & $86.97 \pm 0.64 \%$ & $9.67 \pm 1.80 \%$ & $3.08 \pm 0.20 \%$ & $0.38 \pm 0.19 \%$ \\
\hline & HCT 116 shID1 & $65.42 \pm 2.22 \% *$ & $29.09 \pm 5.10 \% *$ & $4.99 \pm 0.62 \%$ & $0.2 \pm 0.03 \%$ \\
\hline \multirow{2}{*}{$1 \mu \mathrm{M}$ 5-FU } & HCT 116 & $74.86 \pm 1.15 \%$ & $18.91 \pm 0.66 \%$ & $6.68 \pm 0.41 \%$ & $0.22 \pm 0.05 \%$ \\
\hline & HCT 116 shID1 & $43.8 \pm 0.36 \% *$ & $50.12 \pm 3.44 \% *$ & $5.96 \pm 0.64 \%$ & $0.11 \pm 0.01 \%$ \\
\hline
\end{tabular}

pression on biotransformation of the drug. We observed that the mRNA content of thymidine phosphorylase (TYMP) was significantly decreased (6.8-fold) in HT-29shID1 cells compared to parental line (Fig. 5). Some decrease in the expression level of genes encoding uridine-cytydine kinase 2 (UCK2) and dihydropyrimidine dehydrogenase (DPYD) in HT-29shID1 cells was also evident. Suppression of ID1 in HT-29 cells did not affect the expression levels of genes encoding thymidine kinase 1 (TK1), thymidylate synthetase (TYMS), uridine monophosphate synthetase (UMPS), and uridine phosphorylase 1 (UPP1). The transcriptional response to ID1 knock-down in HCT-116 cells was more variable compared to HT-29 line. HCT-116shID1 cells showed significant increase in mRNA levels of TYMP (1.9-fold), TK1 (1.2-fold) and UCK2 (2.0-fold) compared to parental cells. On the other hand, decline in ID1 expression significantly reduced transcript levels of TYMS (2.8-fold) and DPYD (1.5-fold). HCT-116shID1 cells did not exhibit altered expression of UMPS and UPP1 compared to parental line (Fig. 5).

\section{DISCUSSION}

Resistance of colon cancer cells to 5-FU chemotherapeutic is a major obstacle in treatment of people suffering from CRC. In order to include or exclude patients for particular therapeutic regimen predictive biomarkers are used for identification of responsive and nonresponsive individuals. Here, we showed that expression of ID1 belonging to HLH protein family impacts the sensitivity of colon cancer cell lines to 5-FU; thus, making it a candidate for further investigation on potential predictive value.

Knockdown of ID1 resulted in altered expression of mesenchymal and epithelial markers, however, the pattern of changes did not resemble "classical" mesenchymal-epithelial transition (MET). Decreased level of ID1 in HT-29 cells led to a significant reduction of $\mathrm{CDH} 2$ expression but did not affect transcription of $C D H 1$. On the other hand, both genes were upregulated significantly after ID1 suppression in HCT-116 cells. Those observations suggest that depletion of ID1 did not induce cadherin switch, a basic hallmark of MET (Thiery et al., 2009). These results indicate that ID1 expression alone is insufficient to determine an evident shift between the mesenchymal and epithelial phenotype. In number of research devoted to cancer cells direct or indirect suppression of ID1 was shown to correlate with downregulation of EMT markers (Gumireddy et al., 2009; Tobin et al., 2011; Sánchez-Tilló et al., 2014). It was recently revealed, however, that overexpressed ID1 exerts antagonistic effects (Stankic et al., 2013). Upregulation of ID1 generates breast cancer cells with properties of stem cells capable of invasion. It is established that stem celllike characteristic and mesenchymal phenotype closely overlap with each other (Thiery et al., 2009; Stankic et al., 2013). On the other hand, ID1 promotes MET in metastatic breast cancer cells, which have previously undergone EMT (Stankic et al., 2013). This dual mode of ID1 action depends on local expression of twist family bHLH transcription factor 1 (TWIST1) and snail family transcriptional repressor 1 . Those transcriptional inducers and regulators of EMT differentially modulate ID1 function (Stankic et al., 2013). Moreover, the present knowledge on the transition between epithelial and mesenchymal phenotypes suggests that it is not a binary process and many tumor cells acquire an intermediate $\mathrm{E} / \mathrm{M}$ states rather than evident shifts between two phenotypes. These transitional forms are called hybrid epithelial/mesenchymal phenotype (Jolly et al., 2015). It was also noted that stable lentiviral ID1 overexpression producing functional protein in melanoma cells failed to affect transcription/translation of the ID1 target genes suggesting that ID1 expression alone is insufficient to determine cell fate (Healey et al., 2010). Thus, it may be assumed that specific response triggered by ID1 depends on molecular context in the cancer cell or its environment. Further investigations should be made in order to reveal the role of this protein in signaling cascades and loops governing epithelial-mesenchymal plasticity.

We showed that suppression of ID1 resulted in an increased proliferation rate of both examined cell lines. Available data on the impact of ID1 on cancer cells proliferation varies depending on cancer type and experimental methodology. Stankic's work (Stankic et al., 2013) reported that suppression of ID1 in breast cancer cells cultivated in a complete medium did not affect proliferation rate. On the contrary, it was shown that ID1 silencing in salivary gland cancer cells decreased proliferation rate irrespectively of FBS presence (Sumida et al., 2013). In our experiments we utilized MTT method which measures metabolic activity in viable cells and under certain conditions is considered as valuable tool for assessment of proliferation (Berridge et al., 1996). We also calculated 
DT values of cells basing exclusively on the phases of exponential growth. Moreover, normalized data sets were used (at $t_{1} y=1$ ) which allowed comparing only dynamics of growth between examined cell lines. Thus, the lack of universal approach for analysis of cellular proliferation leads to somewhat problematic comparison of different results. Under serum starvation condition ID1 silencing did not affect the proliferation, moreover, parental HT-29 cells grew faster than transduced counterparts. FBS is the source of growth factors, including fibroblast growth factor (FGF) (Brunner et al., 2010). In studies on calvarias development FGF2 was shown to promote TWIST1 expression, whereas ID1 antagonized TWIST1 action through blocking dimerization of TWIST1 and transcription factor 3 (TCF3) (Rice et al., 2000; Connerney et al., 2008). T-TCF dimers promote more aggressive phenotype (Gajula et al., 2015) and number of reports showed that TWIST1 enhances proliferation of cancer cells (Hasselblatt et al., 2009; Qian et al., 2013; Qiang et al., 2014; Zhang et al., 2015; Zhu et al., 2015; Li \& Wu, 2016). Thus, the observed increase of FBS-dependent cell growth after ID1 silencing might be the result of enhanced formation of T-TCF heterodimers.

In our study we observed differential response of examined cell lines to 5-FU treatment. Silencing of ID1 in HT-29 cells did not affect the sensitivity of these cells to 5-FU, whereas HCT-116 cells were significantly sensitized to 5 -FU by suppression of ID1. It was recently shown that CRC cells acquire chemoresistance through leukemia inhibitory factor (LIF)-MDM2 axis ( $\mathrm{Yu}$ et al., 2014). LIF protein interacts with signal transducer and activator of transcription 3 and ID1 inducing MDM2 expression. In turn, MDM2 protein promotes degradation of tumor protein p53 (TP53) leading to a generation of cell which is less prone to apoptosis in response to $5-\mathrm{FU}$ (Yu et al., 2014). HT-29 cell line already contains inactive TP53 protein, owing to mutated TP53 gene, which may result in nonfunctional and degradation-resistant TP53 protein uncontrolled by LIF-ID1-MDM2 axis. Such a mechanism may explain why ID1 suppression failed to enhance the sensitivity of HT-29 cells to 5-FU. Impaired TP53 could also account for differences between HT-29 and HCT-116 cell lines observed in flow cytometric analysis. Under normal conditions as well as in the presence of 5-FU parental and transduced HT-29 cells exhibited higher viability and smaller apoptotic fractions compared to HCT-116 counterparts.

Cellular conversion of 5-FU may lead, through metabolic activation or degradation, to fluoro- $\beta$-alanine (F-BAL) (Longley et al., 2003). DPYD catalyses transformation of 5-FU to 5-fluoro-5,6-dihydrouracil (5-FDHU) and this reaction is the primary rate-limiting step in degradation of 5-FU. Responsiveness of patients to 5-FU treatment was shown to depend on the drug catabolism (Etienne et al., 1995). Level of DPYD expression is related to sensitivity to 5-FU. Recent study on hepatocellular carcinoma cell lines revealed that indirect modulation of $D P Y D$ transcription correlated with 5-FU-mediated decrease in cells proliferation (Oie et al., 2007). Suppression of DPYD expression in HCT-116 cells produced stronger apoptotic effect of 5-FU (Offer et al., 2014). In our experiment depletion of ID1 resulted in a similar range of DPYD downregulation in both HT-29 and HCT-116 cells. Thus, it may be assumed that differences in the response to 5-FU of these cell lines do not depend on DPYD expression level.

In the cell, 5-FU activation proceeds either through synthesis of 5-fluorouridine-5'-monophosphate (FUMP) or generation of FdUMP (Longley et al., 2003). Pro- duction of FUMP may be catalyzed in direct manner by UMPS or sequentially by transformation of 5-FU to 5-fluorouridine (FUR) via UPP and subsequent production of FUMP catalyzed by UCK. FdUMP, on the other hand, is produced through conversion of 5-FU to 5'-deoxy-5-fluorouridine (FdUR) catalyzed by TYMP and subsequent TK-dependant modification to FdUMP. Suppression of ID1 in HT-29 cells resulted in decreased expression of TYMP and did not alter transcription of TK1 and TYMS. HCT-116shID1 cells, on the contrary, exhibited increased mRNA levels of TYMP and TK1 concomitant with depletion of TYMS transcript. It may, therefore, be suspected that sensitization of HCT-116shID1 cells to 5-FU might be due to enhanced FdUMP production. However, according to current data major pathway of 5-FU anabolism does not lead through generation of FdUMP but rather through production of FUMP (Peters et al., 1986; Peters et al., 1991). ID1 suppression in both examined cell lines affected only the expression of UCK2, although differentially. UCK2 was upregulated in HCT-116shID1 which suggests that increased response to 5-FU in these cells is related, at least partially, with enhanced activation of drug through FUMP synthesis.

In conclusion, we showed here that the low level of ID1 in colon cancer cells may sensitize these cells to 5-FU cytotoxicity, although the ID1 effect is differentially modified by mutations present in cancer cells. We assume that the determination of ID1 expression level together with other markers may help more precisely identify patients which may respond positively to 5-FU treatment.

\section{Acknowledgements}

This work was partially realized using the resources of the Cellular Function and Pathology Imaging Network of the Medical University of Gdańsk and the University of Gdańsk.

This work was supported by Medical University of Gdansk research grant MN 01-0231/08/249 to TP.

\section{REFERENCES}

Berridge M, Tan A, McCoy K, Wang R (1996) The biochemical and cellular basis of cell proliferation assays that use tetrazolium salts. Biochemica 4: 14-19

Brunner D, Frank J, Appl H, Schöffl H, Pfaller W, Gstraunthaler G (2010) Serum-free cell culture: the serum-free media interactive online database. Altex 27: 53-62

Cheng YJ, Lee YC, Chiu WC, Tsai JW, Su YH, Hung AC, Chang PC, Huang CJ, Chai CY, Yuan SS (2014) High Id1 expression, a generally negative prognostic factor, paradoxically predicts a favorable prognosis for adjuvant paclitaxel plus cisplatin therapy in surgically treated lung cancer patients. Oncotarget 5: 11564-11575. http:// dx.doi.org/10.18632/oncotarget.2595

Connerney J, Andreeva V, Leshem Y, Mercado MA, Dowell K, Yang X, Lindner V, Friesel RE, Spicer DB (2008) Twist1 homodimers enhance FGF responsiveness of the cranial sutures and promote suture closure. Dev Biol 318: 323-334. http://dx.doi.org/10.1016/j. ydbio.2008.03.037

Etienne MC, Cheradame S, Fischel JL, Formento P, Dassonville O, Renee N, Schneider M, Thyss A, Demard F, Milano G (1995) Response to fluorouracil therapy in cancer patients: the role of tumoral dihydropyrimidine dehydrogenase activity. J Clin Oncol 13: 1663-1670

Gajula RP, Chettiar ST, Williams RD, Nugent K, Kato Y, Wang H, Malek R, Taparra K, Cades J, Annadanam A, Yoon AR, Fertig E, Firulli BA, Mazzacurati L, Burns TF, Firulli AB, An SS, Tran PT (2015) Structure-function studies of the bHLH phosphorylation domain of TWIST1 in prostate cancer cells. Neoplasia 17: 16-31. http://dx.doi.org/10.1016/j.neo.2014.10.009

Graham JS, Cassidy J (2012). Adjuvant therapy in colon cancer. Exp Rev Anticancer Ther 12: 99-109. http://dx.doi.org/10.1586/era.11.189 Gumireddy K, Li A, Gimotty PA, Klein-Szanto AJ, Showe LC, Katsaros D, Coukos G, Zhang L, Huang Q (2009) KLF17 is a negative 
regulator of epithelial-mesenchymal transition and metastasis in breast cancer. Nat Cell Biol 11: 1297-1304. http://dx.doi.org/10.1038/ ncb1974

Hammond WA, Swaika A, Mody K (2016) Pharmacologic resistance in colorectal cancer: a review. Ther Adv Med Oncol 8: 57-84. http:// dx.doi.org/10.1177/1758834015614530

Hasselblatt M, Mertsch S, Koos B, Riesmeier B, Stegemann H, Jeibmann A, Tomm M, Schmitz N, Wrede B, Wolff JE, Zheng W, Paulus W (2009) TWIST-1 is overexpressed in neoplastic choroid plexus epithelial cells and promotes proliferation and invasion. Cancer Res 69: 2219-2223. http://dx.doi.org/10.1158/0008-5472.CAN08-3176

Healey MA, Deaton SL, Alder JK, Winnepenninckx V, Casero RA Jr, Herman JG (2010) Id1 overexpression is independent of repression and epigenetic silencing of tumor suppressor genes in melanoma. Epigenetics 5: 410-421

Jolly MK, Boareto M, Huang B, Jia D, Lu M, Ben-Jacob E, Onuchic JN, Levine H (2015) Implications of the Hybrid Epithelial/Mesenchymal Phenotype in Metastasis. Front Oncol 5: 155. http://dx.doi. org/10.3389/fonc. 2015.00155

Kelder W, Hospers GAP Plukker JTM (2006) Effects of 5-fluorouracil adjuvant treatment of colon cancer. Exp Rev Anticancer Ther 6: 785-794. http://dx.doi.org/10.1586/14737140.6.5.785

Li B, Tsao SW, Chan KW, Ludwig DL, Novosyadlyy R, Li YY, He QY, Cheung AL (2014) Id1-induced IGF-II and its autocrine/ endocrine promotion of esophageal cancer progression and chemoresistance - implications for IGF-II and IGF-IR-targeted therapy. Clin Cancer Res 20: 2651-2662. http://dx.doi.org/10.1158/10780432.CCR-13-2735

Li L, Wu D (2016) miR-32 inhibits proliferation, epithelial-mesenchymal transition, and metastasis by targeting TWIST1 in non-smallcell lung cancer cells. Onco Targets Ther 9: 1489-1498. http://dx.doi. org/10.2147/OTT.S99931

Ling F, Kang B, Sun XH (2014) Id proteins: small molecules, mighty regulators. Curr Top Dev Biol 110: 189-216. http://dx.doi. org/10.1016/B978-0-12-405943-6.00005-1

Lombardi L, Morelli F, Cinieri S, Santini D, Silvestris N, Fazio N, Orlando L, Tonini G, Colucci G, Maiello E (2010) Adjuvant colon cancer chemotherapy: where we are and where we'll go. Cancer treatment reviews 36: S34-S41. http://dx.doi.org/10.1016/S03057372(10)70018-9

Longley DB, Harkin DP, Johnston PG (2003) 5-Fluorouracil: mechanisms of action and clinical strategies. Nat Rev Cancer 3: 330-338. http://dx.doi.org/10.1038/nrc1074

Maciejewska I, Sakowicz-Burkiewicz M, Pawelczyk T (2014) Id1 Expression level determines the differentiation of human dental pulp stem cells. J Dental Res 93: 576-581. http://dx.doi. org/10.1177/0022034514530164

Offer SM, Butterflied GL, Jerde CR, Fossum CC, Wegner NJ, Diasio RB (2014) microRNAs miR-27a and miR-27b directly regulate liver dihydropyrimidine dehydrogenase expression through two conserved binding sites. Mol Cancer Ther 13: 742-751. http://dx.doi. org/10.1158/1535-7163.MCT-13-0878

Oie S, Ono M, Fukushima H, Hosoi F, Yano H, Maruyama Y, Kojiro M, Terada T, Hirano K, Kuwano M, Yamada Y (2007) Alteration of dihydropyrimidine dehydrogenase expression by IFN- $\alpha$ effects the antiproliferative effects of 5-fluorouracil in human hepatocellular carcinoma cells. Mol Cancer Ther 6: 2310-2318. http://dx.doi. org/10.1158/1535-7163.MCT-06-0281
Oyan B (2012) Why do targeted agents not work in the adjuvant setting in colon cancer? Exp Rev Anticancer Ther 12: 1337-1345. http:// dx.doi.org/1586/era.12.111

Peng JJ, Wu B, Xiao XB, Shao YS, Feng Y, Yin MX (2014). Reduced Kruppel-like factor 17 (KLF17) expression correlates with poor survival in patients with gastric cancer. Arch Med Res 45: 394-399. http://dx.doi.org/10.1016/j.arcmed.2014.06.005

Peters GJ, Laurensse E, Leyva A, Lankelma J, Pinedo HM (1986). Sensitivity of human, murine, and rat cells to 5-fluorouracil and 5'-deoxy-5-fluorouridine in relation to drug-metabolizing enzymes. Cancer Res 46: 20-28

Peters GJ, van Groeningen CJ, Laurensse EJ, Pinedo HM (1991) A comparison of 5-fluorouracil metabolism in human colorectal cancer and colon mucosa. Cancer 68: 1903-1909

Qian J, Luo Y, Gu X, Zhan W, Wang X (2013) Twist1 promotes gastric cancer cell proliferation through up-regulation of FoxM1. PLoS One 8: e77625. http://dx.doi.org/10.1371/journal.pone.0077625

Qiang L, Zhao B, Ming M, Wang N, He TC, Hwang S, Thorburn A, He YY (2014) Regulation of cell proliferation and migration by $\mathrm{p} 62$ through stabilization of Twist1. Proc Natl Acad Sci USA 111: 92419246. http://dx.doi.org/10.1073/pnas.1322913111

Rice DP, Aberg T, Chan Y, Tang Z, Kettunen PJ, Pakarinen L, Maxson RE, Thesleff I (2000) Integration of FGF and TWIST in calvarial bone and suture development. Development 127: 1845-1855

Sánchez-Tilló E, de Barrios O, Siles L, Cuatrecasas M, Castells A, Postigo A (2014) ID1 regulates U87 human cell proliferation and invasion. Clin Cancer Res 20: 2651-2662. http://dx.doi.org/10.3892/ ol.2013.1507

Stankic M, Pavlovic S, Chin Y, Brogi E, Padua D, Norton L, Massagué J, Benezra R (2013) TGF- $\beta-I d 1$ signaling opposes Twist1 and promotes metastatic colonization via a mesenchymal-to-epithelial transition. Cell Rep 5: 1228-1242. http://dx.doi.org/10.1016/j.celrep.2013.11.014

Sumida T, Murase R, Onishi-Ishikawa A, McAllister SD, Hamakawa H, Desprez PY (2013) Targeting Id1 reduces proliferation and invasion in aggressive human salivary gland cancer cells. BMC Cancer 13: 141. http://dx.doi.org/10.1186/1471-2407-13-141

Thiery JP, Acloque H, Huang RY, Nieto MA (2009) Epithelial-mesenchymal transitions in development and disease. Cell 139: 871-890. http://dx.doi.org/10.1016/j.cell.2009.11.007

Tobin NP, Sims AH, Lundgren KL, Lehn S, Landberg G (2011) Cyclin D1, Id1 and EMT in breast cancer. BMC Cancer 11: 417. http:// dx.doi.org/10.1186/1471-2407-11-417

Yu H, Yue X, Zhao Y, Li X, Wu L, Zhang C, Liu Z, Lin K, XuMonette ZY, Young KH, Liu J, Shen Z, Feng Z, Hu W (2014) LIF negatively regulates tumour-suppressor p53 through Stat3/ID1/ MDM2 in colorectal cancers. Nat Commun 5: 5218. http://dx.doi. org/0.1038/ncomms6218

Zhang H, Gong J, Kong D, Liu HY (2015) Anti-proliferation effects of Twist gene silencing in gastric cancer SGC7901 cells. World J Gastroenterol 21: 2926-2936. http://dx.doi.org/10.3748/wjg.v21. i10.2926

Zhu DJ, Chen XW, Zhang WJ, Wang JZ, Ouyang MZ, Zhong Q, Liu CC (2015) Twist1 is a potential prognostic marker for colorectal cancer and associated with chemoresistance. Am J Cancer Res 5: 2000-2011 